\title{
Optimization of Ingredient Levels for Production of Low Calorie Herbal Basundi Using Response Surface Methodology (RSM)
}

\author{
K.N. Sai Sreenivas ${ }^{1} *$ and S.N. Rajakumar ${ }^{2}$ \\ ${ }^{1}$ Department of Dairy Technology, Dairy Science College, Hebbal, Bengaluru, \\ Karnataka-560024, India \\ ${ }^{2}$ Department of Dairy Technology, College of Dairy Science and Technology, Mannuthy, \\ Thrissur, Kerala-680651, India \\ *Corresponding author
}

\section{A B S T R A C T}

Keywords Basundi, Low calorie, herbal, Response Surface Methodology (RSM), Hemidesmus indicus, Bougainvillea glabra

Article Info

Accepted:

06 June 2018

Available Online:

10 July 2018
Low calorie herbal basundi was developed under the current study using sucralose as low calorie sweetener, Hemidesmus indicus and Bougainvillea glabra as herbs with health beneficial properties. As per preliminary trials, the range of levels of sucralose, Hemidesmus indicus and Bougainvillea glabra were fixed as 60 to $80 \mathrm{ppm}, 0.5$ to 1.5 per cent and 0.1 to 0.3 per cent respectively. Central Composite Rotatable Design (CCRD) of Response Surface Methodology (RSM) with three variables (Sucralose, Hemidesmus indicus and Bougainvillea glabra) and five responses comprising of sensory attributes was used for computation of optimized solution. All the responses fitted well into quadratic equation with $\mathrm{R}^{2}>0.87$. The optimum level of ingredient combinations recommended with 92 per cent desirability was obtained. The optimum levels comprised of concentration of sucralose at $70.98 \mathrm{ppm}$ level, Hemidesmus indicus at 0.98 per cent level and Bougainvillea glabra at 0.20 per cent level for maximum acceptability of low calorie herbal basundi.

\section{Introduction}

Dairy products offer an important food source for human health and nutrition in India as a chief percentage of population being vegetarians. Indian dairy has noticed an inconceivable growth in milk production. About 50-55 per cent of the milk produced in India is changed into a variety of traditional dairy products like Khoa and Channa based, Ghee, Paneer, Dahi and concentrated milk products such as Rabri, Basundi and Malai etc. (Singh et al., 2009). "Basundi which has a sweetish caramel aroma is a heat-desiccated, thickened milk dessert, having white to light caramel colour, creamy consistency with soft textured flakes that are uniformly suspended throughout the product matrix." It is a dessert which is consumed directly and has sugar and all the milk solids in an estimated two-fold concentration that renders it a high nutritive value (Aneja et al., 2002).

Low calorie sweeteners have been successfully used as a replacement to sucrose in a broad range of dairy products. Ministry of Health and Family Welfare under Government of India made Amendments to PFA Act rules, 
1995 such that artificial sweeteners are used inside prescribed limits and were permitted with proper label declaration. Different lowcalorie sweeteners such as saccharin, acesulfame K, aspartame and sucralose have been permitted in the dairy products like khoa, burfi, and rasogolla (FSSAI, 2012). Use of high potency low calorie sweetener like sucralose by complete or partial replacement of calorie loaded sucrose in several food products has been attempted to decrease total calorie intake (Morlock and Prabha, 2007). Management of lifestyle diseases such as obesity or diabetes mellitus has become much easier amid such dietary options (Kroger et al., 2006). Sucralose, a non-nutritive sweetener is the one commonly used that is about 320 to 1000 times as sweet as sugar has been effectively used in traditional beverages, baked products, confectionery, dairy desserts, flavoured milks, kulfi, kheer and basundi.

A significant portion of today's functional food market consists of herbal supplemented functional foods. Dairy products, popular throughout the country, can be used efficiently as carriers for herbs to satisfy the needs of health conscious consumers. Functional components present in the herbs aids in executing a large range of biological functionalities. Among the herbs are Hemidesmus indicus and Bougainvillea glabra native to state of Kerala have been documented to have health benefits. As stated by Khanna and Kannabiran (2007), Hemidesmus indicus is also known as Anantamul in Hindi, Nannari in Tamil whose root extracts are used as a coolant and a blood purifier. Various effects of Hemidesmus indicus, such as hypoglycemic, hypolipidemic, antioxidant, antiulcerogenic etc., have been reported (Lakshmi and Rajendran, 2013). Bougainvillea is a genus of bright flowering plants belonging to the Nyctaginaceae family and is also called as paper flower having shiny green and magenta or purple colored bracts (Kumar et al., 2013). Among the
Bougainvillea's varieties include Bougainvillea glabra, Bougainvillea spectabilis, and Bougainvillea harrisi (Adebayo et al., 2009). Bougainvillea spectabilis is used in herbal combination for the treatment of diabetes (Simmonds and Howes, 2006). Information also exists about the use of Bougainvillea glabra in the cure of ulcer, diarrhoea, and having anti-microbial activities (Edwin et al., 2007). Considering the above facts, present study was undertaken with the objective of optimizing the ingredient levels for preparation of low-calorie herbal basundi.

\section{Materials and Methods}

\section{Raw materials}

Cow milk: Cow milk was procured from Kerala Veterinary University Dairy Plant, Mannuthy.

Sucralose: Food grade sucralose was procured from JK Sucralose Inc., Beijing, China.

Hemidesmus indicus: The powdered roots of Hemidesmus indicus were purchased from Faizan and co. Pvt. Ltd., Thrissur.

Bougainvillea glabra: The flowers of Bougainvillea glabra were procured from campus of College of Veterinary and Animal Sciences, Mannuthy.

Chemicals: The Analytical Reagent (AR) grade chemicals were procured from reputed firms.

\section{Preparation of Hemidesmus indicus root extract}

The root extract of Hemidesmus indicus was prepared by the method as described in Ananthi et al., (2010). $300 \mathrm{~g}$ of shade-dried and powdered roots were soaked in 3 liters of autoclaved distilled water for $48 \mathrm{~h}$ at $20^{\circ} \mathrm{C}$. The filtrate was steam distilled to obtain the flavour distillate of Hemidesmus indicus, which was then stored at $4^{\circ} \mathrm{C}$ until further use. 
Preparation of Bougainvillea glabra flower extract

The aqueous extract of Bougainvillea glabra flower was prepared as per the procedure mentioned by Kalirajan et al., (2012). The shade dried flower of this plant of about $100 \mathrm{~g}$ was taken in a beaker and mixed with $400 \mathrm{ml}$ of sterile distilled water and boiled to heat at $100^{\circ} \mathrm{C}$ with constant stirring in a boiling water bath for about 30 minutes. After cooling, the beaker extract was filtered using a filter paper inside the laminar air flow chamber and stored in refrigerator at $4^{\circ} \mathrm{C}$ for further usage.

\section{Preparation of low calorie herbal basundi}

Basundi was prepared as outlined in Aneja et al., (2002). Cow milk was thickened through evaporative heating with occasional stirring at the bottom. The thickening of the milk increased with continuous boiling. For preparing low calorie herbal basundi, during boiling sucralose was added and stirred into milk until it was fully dissolved and the milk was concentrated further to the consistency of the condensed milk. The pan was then removed from the fire, allowed to cool and the extracts of Hemidesmus indicus and Bougainvillea glabra were added and mixed well for uniform distribution. The ingredients that are sucralose, Hemidesmus indicus and Bougainvillea glabra were added at certain level as suggested by RSM.

\section{Experimental design and statistical analysis}

The statistical analysis for low calorie herbal basundi production was performed by using Design Expert (V 9.0.; Stat-Ease Inc., Minneapolis, MN, USA) software. Central Composite Design (CCD) was used to study the interaction of process variables by applying Response Surface Methodology (RSM). There are 3 variables which are amount of sucralose $\left(\mathrm{X}_{1}\right)$, amount of
Hemidesmus indicus $\left(\mathrm{X}_{2}\right)$ and amount of Bougainvillea glabra $\left(\mathrm{X}_{3}\right)$. Each variable has 3 different coded levels, from low $(-1)$, to medium (0), and high (+1) as well as the star points $(-\alpha$ and $+\alpha)$. The range of sucralose is between 60 to $80 \mathrm{ppm}, 0.5$ to 1.5 per cent for Hemidesmus indicus and 0.1 to 0.3 per cent for Bougainvillea glabra. These were fixed as per the preliminary trials. The design matrix of CCD and also experimental results for the responses of low calorie herbal basundi are shown in Table 1. Flavour $\left(\mathrm{Y}_{1}\right)$, colour $\left(\mathrm{Y}_{2}\right)$, mouth feel $\left(\mathrm{Y}_{3}\right)$, body and texture $\left(\mathrm{Y}_{4}\right)$ and overall acceptability $\left(\mathrm{Y}_{5}\right)$ were taken as the responses of the design experiment. The full quadratic equation of the response variables for yogurt was derived by using RSM as Eq. 1.

$Y=\beta_{0}+\beta_{1} X_{1}+\beta_{2} X_{2}+\beta_{3} X_{3}+\beta_{11} X_{1}{ }^{2}+\beta_{22} X_{2}{ }^{2}+\beta_{33} X_{3}$

${ }^{2}+\beta_{12} X_{1} X_{2}+\beta_{13} X_{1} X_{3}+\beta_{23} X_{2} X_{3}(1)$

Where,

$Y=$ responses; $\beta_{0}=$ constant; $\beta_{1}, \beta_{2}, \beta_{3}=$ linear regression; $\beta_{11}, \beta_{22}, \beta_{33}=$ interaction regression; $\mathrm{X}_{1}, \mathrm{X}_{2}, \mathrm{X}_{3}=$ variables.

Quantitative descriptive analysis of low calorie herbal basundi

Sensory evaluation of the produced basundi was conducted among 6-trained panellists in College of Dairy Science and Technology, Mannuthy. Samples of $20 \mathrm{~mL}$ were put and served in a plastic container and coded alphabetically. The estimated parameters of model for sensory attributes and responses of low calorie herbal basundi are shown in Table 2.

\section{Preference test for low calorie herbal} basundi

The basundi characteristics were evaluated using 9-point hedonic scale (1=extremely 
disliked; 9=extremely liked) for various characteristics such as flavour, colour, mouth feel, body and texture and overall acceptability.

\section{Results and Discussion}

\section{Model fitting for RSM}

The experimental results on the amount of sucralose $\left(\mathrm{X}_{1}\right)$, amount of $H$. indicus $\left(\mathrm{X}_{2}\right)$ and amount of B. glabra $\left(\mathrm{X}_{3}\right)$ on the development of low calorie herbal basundi are shown in Table 1. The sensorial quality of the basundi was evaluated as the responses for the factors studied. The quality of basundi based on sensory evaluation was rated based on the flavour $\left(\mathrm{Y}_{1}\right)$, colour $\left(\mathrm{Y}_{2}\right)$, mouth feel $\left(\mathrm{Y}_{3}\right)$, body and texture $\left(\mathrm{Y}_{4}\right)$ and also the overall acceptability $\left(\mathrm{Y}_{5}\right)$ of the basundi as responded by the panellists.

Both the manipulated variables and responses were fitted to the quadratic model by performing the analysis of variance (ANOVA).

The experimental results were analyzed to determine the lack of fit and the significance of the quadratic model and the effect of interaction between the manipulated variables and responses. According to Gan et al., (2007), the lack of fit test is a measurement of the failure of a model to represent the experimental data at the point excluded in the regression while Lima et al., (2010), discovered that the goodness-of-fit of the model was identified by the coefficient of determination $\left(\mathrm{R}^{2}\right)$ and it should be at least approximately $80 \%$. This author also mentioned that p-value is a tool to check the significant of each coefficient. Greater F-value and smaller p-value represent better significant of the corresponding coefficient.

The results obtained from the ANOVA analysis are shown in Table 2 . The $\mathrm{F}$ and $\mathrm{p}$ - values of $<0.05$ indicate that the quadratic model of the coconut milk yogurt development is statistically significant at $95 \%$ confidence interval. The lack of fit for each response is insignificant. The $\mathrm{R}^{2}$ values for the flavour, colour, mouth feel, body and texture and overall acceptability are more than or equal to $87 \%$ indicating that only $13 \%$ of the data cannot be interpreted by the model which indicates that a high proportion of variability is well explained by the model.

\section{Effect on flavour}

The sensory scores for flavour of low calorie herbal basundi ranged from 7.42 to 8.58 (Table 1). The maximum scores were obtained for trial numbers 16 and 20 while the minimum score was for trial numbers 3 and 9 (Table 1). The quadratic model for flavour was obtained through successive regression analysis. The dependence of flavour with respect to three factor levels in the form of correlations is presented in the Table 2. The model F-value for flavour was more than the table F-value at five per cent level of significance $(p<0.05)$. The coefficient of determination $\left(\mathrm{R}^{2}\right)$ of 0.96 with adequate precision of 13.42 strongly recommends the use of this response viz. flavour to navigate the design. The lack of fit test, which measures the fitness of the model obtained, did not result in a significant F-value, indicating that the model is sufficiently accurate for predicting the flavour of low calorie herbal basundi. The coefficient estimates (p-value) of the flavour model (Table 2) showed that sucralose (A) had no significant $\quad(\mathrm{p} \geq 0.05) \quad$ effect, whereas Hemidesmus indicus (B) and Bougainvillea glabra $(\mathrm{C})$ effected significantly $(\mathrm{p}<0.05)$ the flavour score of low calorie herbal basundi. Both $\mathrm{B}$ and $\mathrm{C}$ affected the flavour negatively at quadratic levels (Fig. 1b and 1c). Figure 1b and 1c shows that flavour score decreases as B and $\mathrm{C}$ increases, reaches maximum score at intermediate time and then gradually 
decreases. This may be probably due to off flavour of the herb at higher concentrations that affects the flavour scores. All three factors were non-significant ( $\mathrm{p} \geq 0.05)$ at squared level. The interaction among the three factors had a significant $(p<0.05)$ effect on flavour score and in which interaction of $\mathrm{A}$ and $\mathrm{C}$ i.e. $\mathrm{AC}$ had a negative effect. Findings reported by Gautam et al., (2012) showed similar variation in flavour scores of chhana kheer.

\section{Effect on colour}

The sensory scores for colour of low calorie herbal basundi ranged from 7.42 to 8.66 (Table 1). The maximum scores was obtained for trial numbers 16 and 20 and minimum score was for trial number 9 (Table 1). The quadratic model for colour was obtained through successive regression analysis. The dependence of flavour with respect to three factor levels in the form of correlations is presented in the Table 2. The model F-value for flavour was more than the table F-value at five per cent level of significance. The coefficient of determination $\left(\mathrm{R}^{2}\right)$ of 0.97 with adequate precision of 15.61 strongly recommends the use of this response viz. colour to navigate the design. The lack of fit test, which measures the fitness of the model obtained, did not result in a significant Fvalue, indicating that the model is sufficiently accurate for predicting the colour of low calorie herbal basundi. The sign of partial coefficients suggested that sucralose (A), Hemidesmus indicus (B) and Bougainvillea glabra (C) exerted a significant $(\mathrm{p}<0.05)$, where in $\mathrm{A}$ had a positive effect and the rest two had a negative effect at linear level. At squared level, the effect of all three factors was non-significant $(p \geq 0.05)$. The interaction effects among the factors were found to be significant $(\mathrm{p}<0.05)$. The interaction of $A$ and $\mathrm{B}$ i.e., $\mathrm{AB}, \mathrm{A}$ and $\mathrm{C}$ i.e. $\mathrm{AC}$ was found to be negative, but only AC was significant $(p<0.05)$. The interaction effect of $B$ and $C$ i.e.
BC was both positive and also significant $(p<0.05)$. The three dimensional surface diagrams generated (Fig. 2a to 2c) for colour implied that as level of $\mathrm{A}, \mathrm{B}$ and $\mathrm{C}$ increases the colour scores increases to a maximum level and then decreases. The decrease in sensory scores of colour might be due to addition of herbs which affects the characteristic light brown colour of basundi. Similar variations in colour scores were reported earlier by Jha et al., (2002) in instant kheer mix.

\section{Effect on mouth feel}

It was observed that the sensory scores for mouth feel ranged between 7.4 and 8.5 with different combinations of process parameters (Table 1). The maximum score was obtained for trial numbers 17 and 20 and minimum score for trial number 4 (Table 1). The quadratic model for mouth feel was obtained through successive regression analysis. The dependence of mouth feel with respect to three factor levels in the form of correlations is presented in the Table 2. The model F-value for mouth feel was more than the table F-value at five per cent level of significance. The coefficient of determination $\left(\mathrm{R}^{2}\right)$ of 0.87 with adequate precision of 7.70 strongly recommends the use of this response viz. mouth feel to navigate the design. The lack of fit test, which measures the fitness of the model obtained, did not result in a significant F-value, indicating that the model is sufficiently accurate for predicting the mouth feel of low calorie herbal basundi. The analysis of variance showed that mouth feel depended significantly on Hemidesmus indicus (B) and Bougainvillea glabra (C) at linear levels, while sucralose (A) had no significant effect. The coefficients of estimates of mouth feel model (Table 2) showed B had a negative effect on mouth feel $(\mathrm{p}<0.05)$ and $\mathrm{C}$ affected the mouth feel positively $(\mathrm{p}<0.05)$ (Fig. 5b). The interaction effect of $\mathrm{A}$ and $\mathrm{C}$ i.e. 
$\mathrm{AC}$ was found to be significant $(\mathrm{p}<0.05)$ and positive while the interactions affect of $A$ and $B$ i.e. $A B$ and $B$ and $C$ i.e. $B C$ was found nonsignificant $(p \geq 0.05)$. No significant $(p \geq 0.05)$ effect was observed at squared levels. It can be seen from Figure 3c that with increasing concentration of $\mathrm{C}$, mouth feel also increased to a maximum score and then decreased with further increase. The significant decrease in mouth feel scores might be due to the salt taste of the product resulting from high concentration Bougainvillea glabra.

\section{Effect on body and texture}

The sensory scores for body and texture of low calorie herbal basundi ranged from 7.33 to 8.66 on the hedonic scale (Table 1). The maximum and minimum score was obtained for trial numbers 16 and 9 respectively. The quadratic model for body and texture was obtained through successive regression analysis.

The dependence of body and texture with respect to three factor levels in the form of correlations is presented in the Table 2. The model F-value for body and texture was more than the table F-value at five per cent level of significance. The coefficient of determination $\left(\mathrm{R}^{2}\right)$ of 0.96 with adequate precision of 16.36 strongly recommends the use of this response viz. body and texture to navigate the design.

The lack of fit test, which measures the fitness of the model obtained, did not result in a significant F-value, indicating that the model is sufficiently accurate for predicting the body and texture of low calorie herbal basundi. The linear terms for sucralose (A) and Bougainvillea glabra (C) level was found to have a positive effect, but non-significant ( $>>0.05$ ), while Hemidesmus indicus (B) exerted negative effect. The interactive effects of all the factors were found to be nonsignificant effect $(p \geq 0.05)$. At squared levels, no significant effect was observed. Figure $4 a$ to $4 \mathrm{c}$ shows the response surface plots for body and texture. It can be observed from Figure $6 \mathrm{a}$ that the body and texture scores decreased with increasing levels of B. This can be related to slight dilution of the product leading to loss in consistency. Similar observations in dietetic sandesh were reported by Nalwade et al., (2015).

\section{Effect on overall acceptability}

The overall acceptability scores for low calorie herbal basundi ranged from 7.4 to 8.5 (Table 1). The maximum score was obtained for trial numbers 16 and 19 and minimum score for trial numbers 3, 5, and 9. The quadratic model for overall acceptability was obtained through successive regression analysis.

The dependence of overall acceptability with respect to three factor levels in the form of correlations is presented in the Table 2. The model F-value for overall acceptability was more than the table F-value at five per cent level of significance. The coefficient of determination $\left(\mathrm{R}^{2}\right)$ of 0.97 with adequate precision of 17.79 strongly recommends the use of this response viz. overall acceptability to navigate the design.

The lack of fit test, which measures the fitness of the model obtained, did not result in a significant F-value, indicating that the model is sufficiently accurate for predicting the overall acceptability of low calorie herbal basundi. The analysis of variance indicated that of sucralose (A) exerted positive effect but not significant $(\mathrm{p} \geq 0.05)$ at linear levels and Hemidesmus indicus (B) had a significant $(\mathrm{p}<0.05)$ negative effect on overall acceptability. The quantity of Bougainvillea glabra had no significant effect but it was positive. Also, the effect was non-significant at squared levels. 
Int.J.Curr.Microbiol.App.Sci (2018) 7(7): 815-826

Table.1 Experimental results for low calorie herbal basundi response variables

\begin{tabular}{|c|c|c|c|c|c|c|c|c|}
\hline $\begin{array}{c}\text { Std. } \\
\text { Order }\end{array}$ & A: Sucralose (ppm) & B: $\mathbf{H .}$ indicus $\mathbf{( \% )}$ & C: B. glabra $\mathbf{( \% )}$ & Flavour & Colour & $\begin{array}{c}\text { Mouth } \\
\text { feel }\end{array}$ & $\begin{array}{c}\text { Body and } \\
\text { Texture }\end{array}$ & $\begin{array}{c}\text { Overall } \\
\text { acceptability }\end{array}$ \\
\hline $\mathbf{1}$ & 60 & 0.50 & 0.10 & 7.50 & 7.42 & 7.50 & 7.42 & 7.66 \\
\hline $\mathbf{2}$ & 80 & 0.50 & 0.10 & 7.58 & 7.75 & 8.00 & 7.92 & 7.66 \\
\hline $\mathbf{3}$ & 60 & 1.50 & 0.10 & 7.42 & 7.58 & 7.58 & 7.50 & 7.42 \\
\hline $\mathbf{4}$ & 80 & 1.50 & 0.10 & 7.66 & 7.58 & 7.42 & 7.92 & 7.50 \\
\hline $\mathbf{5}$ & 60 & 0.50 & 0.30 & 7.50 & 7.42 & 7.58 & 7.66 & 7.42 \\
\hline $\mathbf{6}$ & 80 & 0.50 & 0.30 & 7.58 & 7.58 & 7.66 & 7.92 & 7.58 \\
\hline $\mathbf{7}$ & 60 & 1.50 & 0.30 & 7.50 & 7.75 & 7.66 & 7.66 & 7.58 \\
\hline $\mathbf{8}$ & 80 & 1.50 & 0.30 & 7.66 & 7.58 & 8.00 & 7.92 & 7.92 \\
\hline $\mathbf{9}$ & 53.18 & 1.00 & 0.20 & 7.42 & 7.33 & 7.58 & 7.33 & 7.42 \\
\hline $\mathbf{1 0}$ & 86.82 & 1.00 & 0.20 & 7.58 & 7.42 & 7.83 & 7.58 & 7.50 \\
\hline $\mathbf{1 1}$ & 70 & 0.16 & 0.20 & 8.16 & 8.00 & 8.25 & 8.25 & 8.08 \\
\hline $\mathbf{1 2}$ & 70 & 1.84 & 0.20 & 7.75 & 7.75 & 8.08 & 8.16 & 8.00 \\
\hline $\mathbf{1 3}$ & 70 & 1.00 & 0.03 & 7.75 & 8.00 & 7.83 & 7.83 & 7.75 \\
\hline $\mathbf{1 4}$ & 70 & 1.00 & 0.37 & 7.75 & 8.00 & 7.92 & 8.08 & 7.66 \\
\hline $\mathbf{1 5}$ & 70 & 1.00 & 0.20 & 8.50 & 8.43 & 8.33 & 8.50 & 8.33 \\
\hline $\mathbf{1 6}$ & 70 & 1.00 & 0.20 & 8.58 & 8.66 & 8.33 & 8.66 & 8.50 \\
\hline $\mathbf{1 7}$ & 70 & 1.00 & 0.20 & 8.43 & 8.50 & 8.58 & 8.58 & 8.43 \\
\hline $\mathbf{1 8}$ & 70 & 1.00 & 0.20 & 8.43 & 8.50 & 8.33 & 8.33 & 8.43 \\
\hline $\mathbf{1 9}$ & 70 & 1.00 & 0.20 & 8.43 & 8.50 & 8.43 & 8.58 & 8.50 \\
\hline $\mathbf{2 0}$ & 70 & 1.00 & 0.20 & 8.58 & 8.66 & 8.58 & 8.50 & 8.43 \\
\hline
\end{tabular}

Table.2 Analysis of variance of the response variables

\begin{tabular}{|l|c|c|c|c|c|}
\hline \multirow{2}{*}{$\begin{array}{l}\text { Partial } \\
\text { Coefficients }\end{array}$} & \multicolumn{5}{|c|}{ Sensory characteristics } \\
\cline { 2 - 6 } & Flavour & Colour & Mouth feel & Body and Texture & $\begin{array}{c}\text { Overall } \\
\text { Acceptability }\end{array}$ \\
\hline Intercept & 8.50 & 8.55 & 8.44 & 8.53 & 8.44 \\
\hline A-Sucralose & 0.061 & 0.035 & 0.086 & 0.14 & 0.052 \\
\hline B- Hemidesmus indicus & -0.045 & $-7.329 \mathrm{E}-003$ & -0.027 & $-5.218 \mathrm{E}-003$ & $-2.521 \mathrm{E}-003$ \\
\hline C-Bougainvillea glabra & $5.806 \mathrm{E}-003$ & $-8.007 \mathrm{E}-016$ & 0.040 & 0.060 & $7.765 \mathrm{E}-003$ \\
\hline AB & 0.030 & -0.082 & -0.050 & $-1.000 \mathrm{E}-002$ & 0.033 \\
\hline AC & $-1.000 \mathrm{E}-002$ & -0.042 & 0.010 & -0.050 & 0.053 \\
\hline BC & 0.010 & 0.043 & 0.12 & $-1.000 \mathrm{E}-002$ & 0.11 \\
\hline $\mathbf{A}^{\mathbf{2}}$ & -0.38 & -0.44 & -0.30 & -0.40 & -0.37 \\
\hline $\mathbf{B}^{2}$ & -0.22 & -0.26 & -0.14 & -0.13 & -0.16 \\
\hline $\mathbf{C}^{\mathbf{2}}$ & -0.29 & -0.21 & -0.24 & -0.22 & -0.27 \\
\hline & & $\mathbf{M o d e l}$ & & \\
\hline Lack of fit statistics & $0.0571^{n s}$ & $0.2278^{n s}$ & $0.0991^{n s}$ & $0.4361^{n s}$ & $0.1191^{n s}$ \\
\hline Model F value & $24.91^{*}$ & $31.25^{*}$ & $7.67^{*}$ & $25.60^{*}$ & $43.13^{*}$ \\
\hline $\mathbf{R}^{2}$ & 0.96 & 0.97 & 0.87 & 0.96 & 0.97 \\
\hline Press & 1.00 & 0.77 & 2.24 & 0.65 & 0.49 \\
\hline Adeq. Press & 13.419 & 15.607 & 7.704 & 16.362 & 17.791 \\
\hline
\end{tabular}

*-Significant at five per cent level ( $\mathrm{p}<0.05)$, ns-non-significant $(\mathrm{p} \geq 0.05)$ 
Table.3 Constraints and criteria for optimization of low calorie herbal basundi

\begin{tabular}{|l|c|c|c|}
\hline Constraint & Goal & Lower limit & Upper limit \\
\hline Sucralose (ppm) & In range & 60 & 80 \\
\hline Hemidesmus indicus $\mathbf{( \% )}$ & In range & 0.5 & 1.5 \\
\hline Bougainvillea $\mathbf{( \% )}$ & In range & 0.1 & 0.3 \\
\hline Flavour & Maximise & 7.42 & 8.58 \\
\hline Colour & Maximise & 7.33 & 8.66 \\
\hline Mouth feel & Maximise & 7.42 & 8.58 \\
\hline Body and Texture & Maximise & 7.33 & 8.66 \\
\hline Overall acceptability & Maximise & 7.42 & 8.5 \\
\hline
\end{tabular}

Table.4 Solution obtained after response surface analysis

\begin{tabular}{|c|c|c|c|c|}
\hline Sol. No. & Sucralose (ppm) & Hemidesmus indicus (\%) & Bougainvillea glabra (\%) & Desirability \\
\hline $\mathbf{1}$ & 70.98 & 0.98 & 0.20 & 0.92 \\
\hline
\end{tabular}

Table.5 Verification of the optimum formulation

\begin{tabular}{|l|c|c|c|}
\hline Attributes & Predicted value & Observed value & t -value \\
\hline Flavour & 8.50 & $8.44 \pm 0.03$ & $1.820^{\text {ns }}$ \\
\hline Colour & 8.54 & $8.52 \pm 0.05$ & $0.489^{\text {ns }}$ \\
\hline Mouth feel & 8.44 & $8.38 \pm 0.06$ & $0.943^{\text {ns }}$ \\
\hline Body and Texture & 8.54 & $8.55 \pm 0.04$ & $0.234^{\text {ns }}$ \\
\hline Overall acceptability & 8.44 & $8.38 \pm 0.05$ & $1.187^{\text {ns }}$ \\
\hline
\end{tabular}

Figures are the Mean \pm Standard Error of six replications, ns- non significant $(\mathrm{p} \geq 0.05$ )

Fig.1 Response surface plots for flavour score of low calorie herbal basundi

Fig. 1a

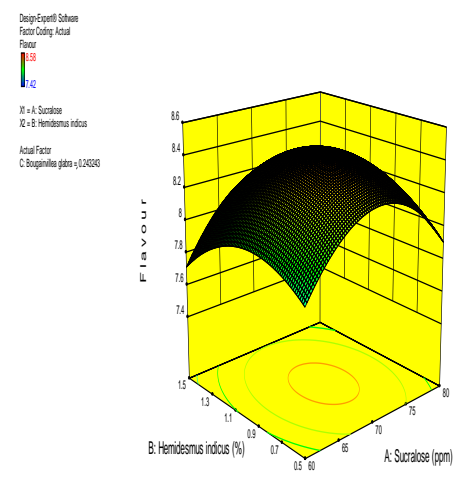

Fig. 1b

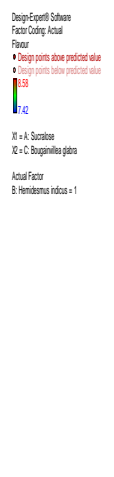

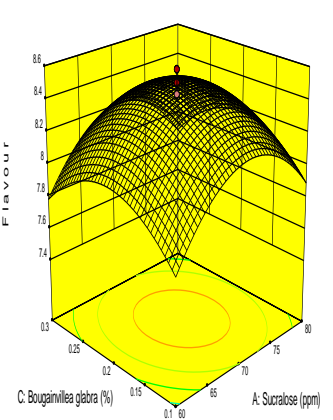

Fig. 1c

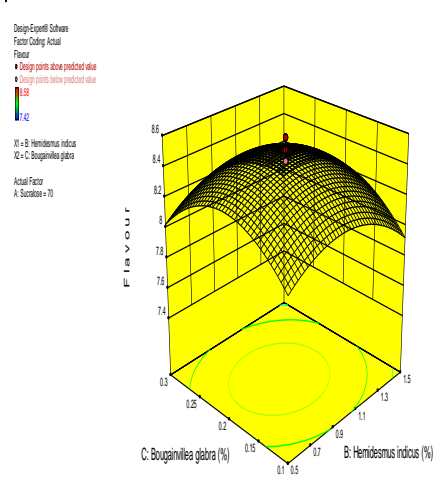


Fig.2 Response surface plots for colour score of low calorie herbal basundi

Fig. $2 \mathrm{a}$

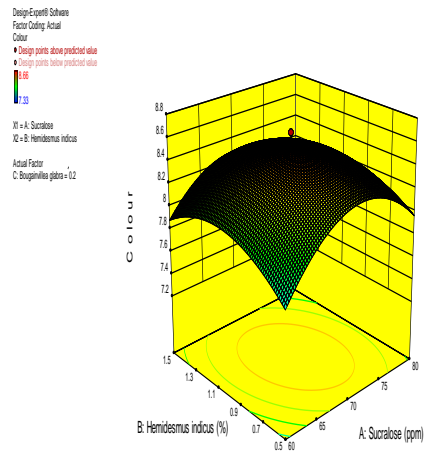

Fig. $2 b$

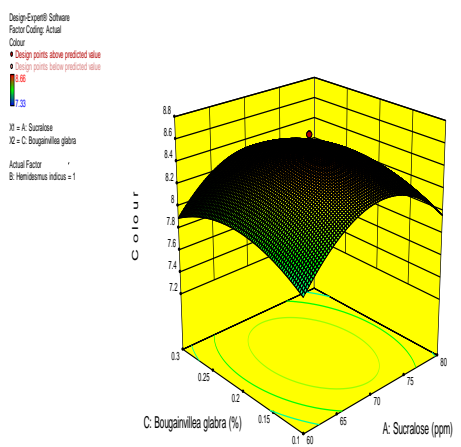

Fig. 2c

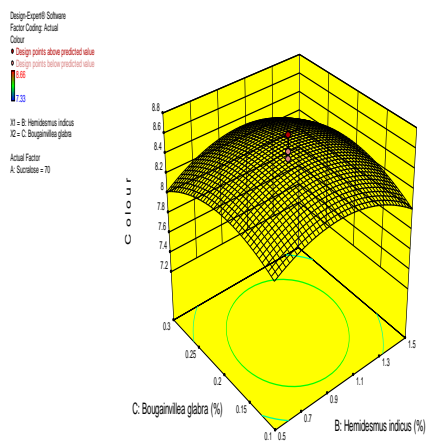

Fig.3 Response surface plots for mouth feel score of low calorie herbal basundi

Fig. 3a

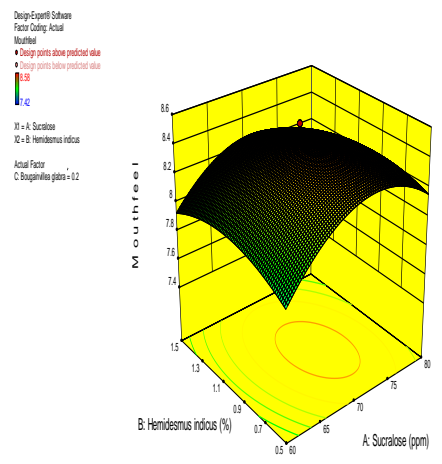

Fig. 3b

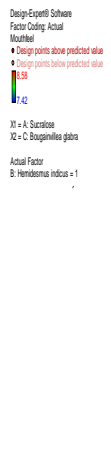

Fig. 3c

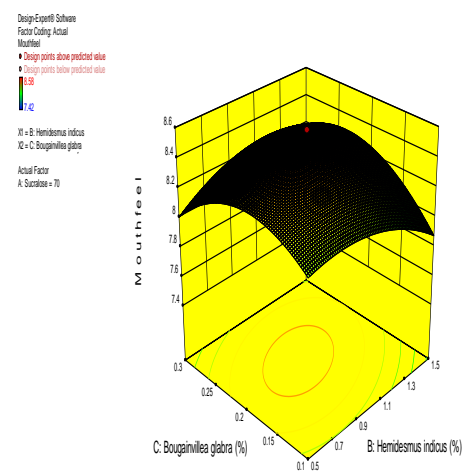

Fig.4 Response surface plots for body and texture score of low calorie herbal basundi

Fig. $4 \mathrm{a}$

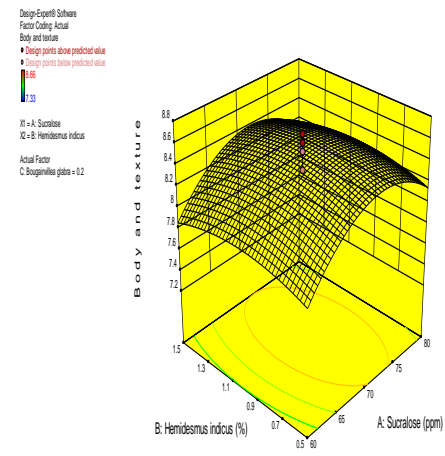

Fig. 4b

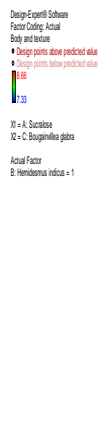

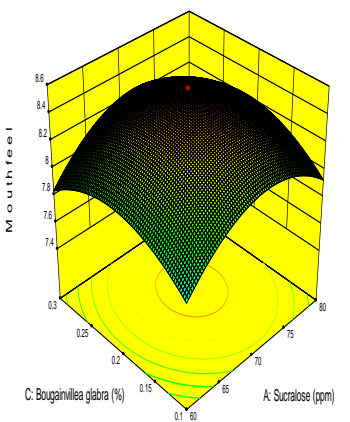

Fig. $4 c$
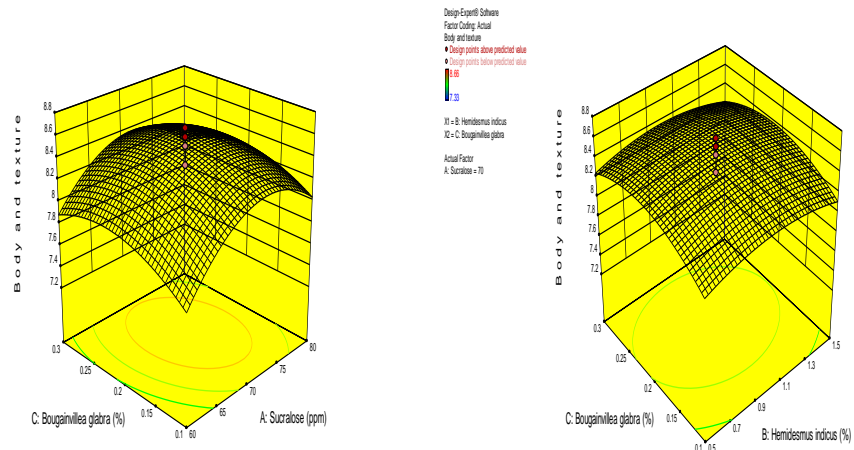
Fig.5 Response surface plots for overall acceptability score of low calorie herbal basundi

Fig. 5a

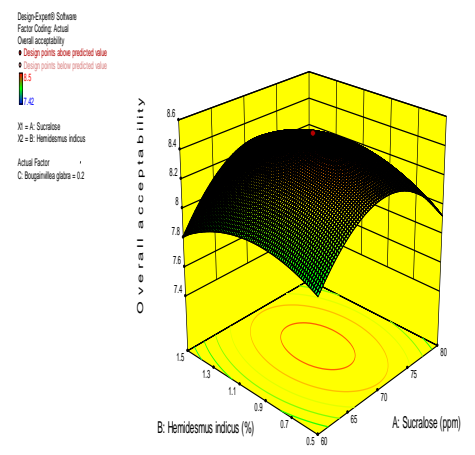

Fig. $5 b$

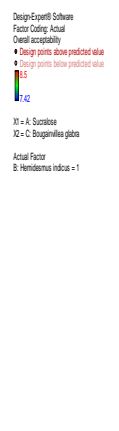

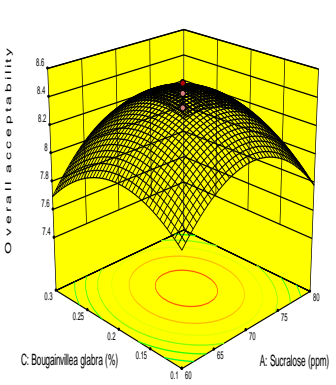

Fig. 5c

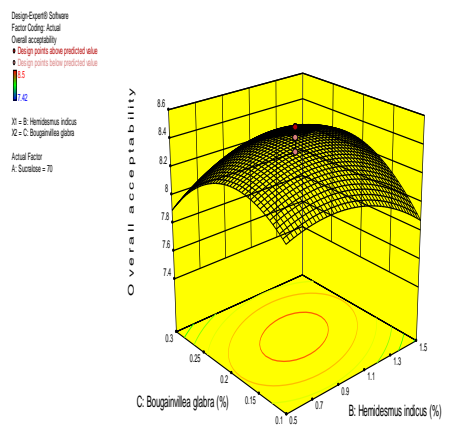

Only the interaction effect of $\mathrm{A}$ and $\mathrm{B}$ i.e. $\mathrm{AB}$ was found to be significant $(p<0.05)$ whereas interaction effects of $\mathrm{A}$ and $\mathrm{C}$ i.e. $\mathrm{AC}$ and $\mathrm{B}$ and $\mathrm{C}$ i.e. $\mathrm{BC}$ was found non-significant $(\mathrm{p} \geq 0.05)$. The 3-D graphs (Fig. 5a to 5c) revealed that as the levels of $\mathrm{A}, \mathrm{B}$ and $\mathrm{C}$ increased the sensory scores for overall acceptability increased to a maximum value and then got reduced. This can be related to two factors which are salt taste of the product resulting from high concentration of Bougainvillea glabra and product losing its consistency because at higher concentrations of Hemidesmus indicus. Similar changes in overall acceptability scores were reported by Singh et al., (2013).

\section{Optimized solutions and their validation}

Numerical optimization was carried out with the objective of best possible combination of sucralose, Hemidesmus indicus and Bougainvillea glabra extracts to yield high quality low calorie herbal basundi. The desired goals for each factor and responses were chosen and different weights were assigned to each goal to adjust the shape of its particular desirability function. Responses were kept maximum and other factors in range during the course of optimization (Table 3). Solution generated by response surface methodology software is shown in Table 4.
The solution had a desirability of 0.92 . The optimum values selected were at $70.98 \mathrm{ppm}$ for sucralose, 0.98 per cent Hemidesmus indicus and 0.20 per cent Bougainvillea glabra extracts. The predicted values for flavour, colour, mouth feel, body and texture and overall acceptability of low calorie herbal basundi were $8.50,8.54,8.44,8.54$ and 8.44 respectively.

\section{Verification of the optimum formulations}

Low calorie herbal basundi prepared using optimized combinations as suggested by Response Surface Methodology (RSM) was subjected to sensory evaluation. The data obtained was statistically analyzed using t-test with the corresponding predicted value. Closeness between the observed and predicted values is depicted in Table 5. It is eminent that the observed values were not significantly $(p \geq 0.05)$ different from the predicted values with respect to all attributes.

In conclusion, Central Composite Rotatable Design (CCRD) of RSM was used to optimize different levels of sucralose, Hemidesmus indicus and Bougainvillea glabra on the responses such as flavour, colour, mouth feel, body and texture and overall acceptability. 
The quadratic model obtained by Response Surface Methodology produced a satisfactory fit to data with respect to flavour $\left(\mathrm{R}^{2}=0.96\right)$, colour $\left(\mathrm{R}^{2}=0.97\right)$, mouth feel $\left(\mathrm{R}^{2}=0.87\right)$, body and texture $\left(\mathrm{R}^{2}=0.96\right)$ and overall acceptability $\left(\mathrm{R}^{2}=0.97\right)$. The formulation with 70.98 ppm sucralose, 0.98 per cent Hemidesmus indicus and 0.2 per cent Bougainvillea glabra was selected. Low calorie herbal basundi was prepared by continuous heating of cow milk with occasional stirring at the bottom and the heat treatment was carried out till desired consistency is obtained in the final product. Sucralose was added during condensing while the herbs Hemidesmus indicus and Bougainvillea glabra were added after the product is cooled. The low calorie herbal basundi thus prepared was then packed in poly propylene cups and kept for storage under refrigeration $\left(7 \pm 1^{\circ} \mathrm{C}\right)$.

\section{Acknowledgments}

The author would like to thank the staff of dairy technology department and allied departments at College of Dairy Science and Technology, Mannuthy.

\section{References}

Adebayo, I.G., Alabi, T.O., Owoyele, V.B. and Soladoye, O.A. 2009. Anti-diabetic properties of the aqueous leaf extract of Bougainvillea glabra (Glory of the Garden) on alloxan-induced diabetic rats. Rec Nat Prod. 3(4): 187-192.

Ananthi, R., Chandra, N. and Santhiya, S.T. 2010. Protective effect of Hemidesmus indicus $\mathrm{R}$. Br. root extract against cisplatin-induced cytogenetic damage in mouse bone marrow cells. Genet and Mol Biol. 33(1): 182-185.

Aneja, R.P., Mathur, B.N., Chandan, R.C. and Banerjee, A.K. 2002. Dairy India $3^{\text {rd }}$ Edition. Baba Barkhanath Printers,
New Delhi. Pp. 126-127.

Edwin, E., Sheeja, E., Toppo, E., Tiwari, V. and Dutt, K.R. 2007. Antidiarrheal, antiulcer and antimicrobial activities of leaves of Bougainvillea glabra Choisy. Ars Pharmaceutica. 48: 135- 144.

FSSAI [Food Safety and Standards Authority of India]. 2012. The Food Safety and Standards Act, Universal Publications, New Delhi. Pp. 450.

Gan, H., Karim, R., Muhammad, S.K., Bakar, J., Hashim, D. and Rahman, R. 2007. Optimization of the basic formulation of a traditional baked cassava cake using response surface methodology. LWTFood Sci Technol. 40: 611-618.

Gautam, A., Jha, A., Singh, R. 2012. Sensory and textural properties of chhana kheer made with three artificial sweeteners. Int J Dairy Technol. 66: 109-118.

Jha, A., Patel, A.A. and Singh, R.R.B. 2002. Physico-chemical properties of instant kheer mix. Lait. 82: 501-513.

Kalirajan, A., Mariselvam, R., Savarimuthu, M.J., Narayanan, K.R., Athi, N.G. and Ranjit, S.A.J.A. 2012. Utilization of Bougainvillea glabra for prepared natural colouring agent and biopesticides. Int J of Curr Res. 4(9): 911.

Khanna, V.G. and Kannabiran, K. 2007. Larvicidal effect of Hemidesmus indicus, Gymnema sylvestre, and Eclipta prostrata against Culex qinquifaciatus mosquito larvae. Afr $\mathrm{J}$ of Biotech. 6(3): 307-311.

Kroger, M., Meister, K. and Kava, R. 2006. Low-calorie sweeteners and other sugar substitutes: A review of the safety issues. Compr Rev Food Sci Food Saf. 5: 35-47.

Kumar, S.N.A., Ritesh, S.K., Sharmila, G. and Muthukumaran, C. 2013. Extraction optimization and characterization of water soluble red purple pigment from floral bracts of Bougainvillea glabra. 
Arabian J of Chem. 5: 1-6.

Lakshmi, T. and Rajendran, R. 2013. Hemidesmus indicus - Commonly known as Indian sarasaparilla - An update. Int J Pharmacol Bio Sci. 4(4): 397-404.

Lima, C.J., Coelho, L. and Contiero, J. 2010.

The use of response surface methodology in optimization of lactic acid production: Focus on medium supplementation, temperature, and $\mathrm{pH}$ control. Food Technol Biotech. 48: 175181.

Morlock, G.E. and Prabha, S. 2007. Analysis and stability of sucralose in a milk based confection by a simple planar chromatographic method. Agric Food Chem. 55: 7217-7223.
Nalwade, V. 2015. Instrumental colour profile of dieteic Sandesh as function of ingredients using response surface methodology. Indian J of Dairy Sci. 67: 6.

Simmonds, M.S.J. and Howes, M.J.R. 2006. Traditional Medicines for Modern Times: Antidiabetic Plants $4^{\text {th }}$ Edition Taylor and Francis Group, UK. Pp. 172.

Singh, H.L., Kalra, K.K. and Singh, B. 2009. A study on cost and returns of indigenous dairy products in Meerut city of western Uttar Pradesh. Prog Agric. 9(1): 26-30.

Singh, J.P., Singh, S.K. and Kalaichelvan, C. 2013. Formulation of nannari based nutrient rich soft drink. Int J Curr Res. 8:21-28.

\section{How to cite this article:}

Sai Sreenivas, K.N. and Rajakumar, S.N. 2018. Optimization of Ingredient Levels for Production of Low Calorie Herbal Basundi Using Response Surface Methodology (RSM). Int.J.Curr.Microbiol.App.Sci. 7(07): 815-826. doi: https://doi.org/10.20546/ijcmas.2018.707.100 